\title{
Mathematical Thought from Ancient to Modern Times
}

\section{MORRIS KLINE}

The author emphasizes the central ideas and great lines of mathematical thought, thus providing a broad historical panorama and a new perspective on what mathematics is, what it has achieved, and what its purposes are today. The book is organized on the basis of the ideas rather than on the men responsible for them, and is largely concerned with developments after 1700 . Text diagrams throughout $£ 12$ OUP New York

\section{What is Mathematical Logic?}

\section{J. N. CROSSLEY and others}

With enthusiasm the authors explore the exciting aspects of mathematical logic for those who have no mathematical training. They make what is often considered an abstruse topic into a lively and approachable book. Gödel's theorems, computability and recursive functions, and consistency and independence in axiomatic set theory, are explained simply and clearly. Text figures throughout $£ 1.40$ paper covers $70 \mathrm{p}$ OPUS

\section{Elementary Logic}

\section{BENSON MATES}

For this new edition of his introduction to formal logic, Professor Mates has made a number of corrections and improvements to the first edition. The extent and variety of exercises have been considerably increased, and a section added in which a proof procedure is set forth for the first order predicate calculus. The book is intended for use in courses in symbolic or mathematical logic. Second edition numerous examples $£ 3$

\section{The Distribution of Prime Numbers}

\section{Large Sieves and Zero-Density Theorems}

\section{N. HUXLEY}

This book aims to present an up-to-date account for graduate students of an important topic in number theory. The author gives some introductory results, then discusses the prime-number theorem, sieves, and work on zeros and prime numbers, including Bombieri's theorem, gaps between prime numbers, and I. M. Vinogradov's representation of odd numbers of sums of primes. 6 text-figures $£ 6.50$ Oxford Mathematical Monographs

\section{Oxford University Press}




\section{Partial Wave Amplitudes and Resonance Poles}

\section{J. HAMILTON and B. TROMBORG}

This book deals with the mathematical aspects of partial wave amplitudes which occur in the dispersion theory approach to elementary particle physics. The first part discusses the uniqueness of the solutions of partial wave dispersion relations; the second examines the location of the second-sheet poles associated with resonances. 57 text-figures $£ 7$ Oxford Mathematical Monographs

\section{Collected Papers of G. H. Hardy}

\section{Volume V: Integral Calculus}

\section{Edited by F. SMITHIES}

The main object of this publication is to render more accessible the papers of the great mathematician, which in their original form appeared in many journals over a period of almost sixty years. The editors have provided introductions to groups of papers, and comments where appropriate. Volumes I-IV are available at $£ 7.50$ each and the work will be complete in seven volumes. Frontispiece $£ 9$

\section{Conceptual Notation and Related Articles GOTTLOB FREGE}

\section{Translated by Terrell Ward Bynum}

This volume, which will serve as a text and as an aid to further research, contains English translations of Frege's early writings in logic and philosophy and of relevant reviews by other leading logicians. Professor Bynum has contributed a biographical essay, introduction, and extensive bibliography. Frontispiece $£ 9.50$

\section{The Structure of Lebesgue Integration Theory}

\section{G. TEMPLE}

This work provides an introductory account of Lebesgue integration for undergraduates, with many exercises and special emphasis on the motivation of the theory. The theory is reduced to its essentials - the techniques of 'bracketing' and of monotone sequences. The necessary theory of sets of points is simplified by using 'characteristic functions'. Sets of zero measure and their application to the differentiation of monotone functions come before the general theory of measure. The Lebesgue-Stieltjes integral is briefly described. 4 text-figures $£ 3.75$

\section{Oxford University Press}

